\title{
Abrasive Elements and Abrasion Resistance Tests for Car Seat Upholstery
}

\author{
Ivona Jerkovic, Josep Maria Pallarés, Monica Ardanuy, PhD, Xavier Capdevila PhD \\ Universitat Politècnica de Catalunya, Terrassa, Barcelona SPAIN \\ Correspondence to: \\ Monica Ardanuy email: monica.ardanuy@upc.edu
}

\begin{abstract}
The weight of textile components in automobiles is expected to rise to $35 \mathrm{~kg}$ by 2020 , and the average lifetime of a vehicle is about 12 years. Car seats are the most important part of the interior decoration, and polyester is the most widely used material in car seat covering. Abrasion resistance tests are used to quantify the duration of car seat upholstery in normal usage, and this is one of the most important requirements. Several testing methods, standards, and car producer specifications have been developed to define the abrasion resistance of specified materials, and pre-tests have been taken to identify parameters for this research.
\end{abstract}

The objective of this study was to compare three abrasion tests with different abrasive elements using car seat upholstery structures. Comparison among abrasion testers and abrasive papers shows statistically significant differences. The relationship between weight loss and abrasion cycles can be modelled by regression equations.

\section{INTRODUCTION}

The automotive industry is one of the largest single markets for technical textiles. An average family car uses over $33 \mathrm{~m}^{2}$ of textiles (about 14-20 kg), and about 15 to $18 \mathrm{~m}^{2}$ (between 5 to $8 \mathrm{~kg}$ ) are used in the passenger compartment. The car seat, as an important component, has major usage, between 6 and $8 \mathrm{~m}^{2}$ [13].

Textiles for automobiles must satisfy very strong requirements for both security and competing demands. The seat constitutes the most important part of the interior decoration. Its security and comfort are studied by automobile manufacturers, seat makers, fabric producers, and textile research centers and universities. Polyester is the most widely used material in car seat coverings; and woven, weft knitted (circular machine), and warp knitted fabrics (tricot and double needle bar machine) are the most used fabric structures [4].
Test methods and standards used for quality assessment are international or institutional standards, such as BS, DIN, ASTM or SAE. Many attempts have been made to harmonize these standards. Special company standards in the automotive industry are used as well to identify the expected characteristics of car seat fabrics. However, performance standards and test methods can differ considerably between these companies, and acceptable standards for one producer can be completely unacceptable for another. Therefore, the testing laboratories must be equipped with different devices to measure the same property.

Table I shows a summary of the requirements for car seat classification, taking into account their relative importance. As shown, the most important physical requirements are abrasion and pilling resistance.

TABLE I. Requirements on cover materials for car seat ("+"means important and "++"very important [5].

\begin{tabular}{|c|c|c|}
\hline Seat requirement & + & ++ \\
\hline \multicolumn{3}{|l|}{ Optic/Aesthetic } \\
\hline - Touch & & ] \\
\hline - Color & & a \\
\hline - Brightness/Dullness & & a \\
\hline Price & & 曰 \\
\hline \multicolumn{3}{|l|}{ Resistant to wear and load } \\
\hline - Light fastness & & a \\
\hline - Abrasion resistance & & 。 \\
\hline - Pilling resistance & & Q \\
\hline - Fastness & & a \\
\hline - Tenacity-elongation & ] & \\
\hline - Dimensional stability & & 口 \\
\hline \multicolumn{3}{|l|}{ Resistant to ageing } \\
\hline - Light resistant & & a \\
\hline - Temperature resistant & & 0 \\
\hline Industrial Production (flexibility) & ] & \\
\hline \multicolumn{3}{|l|}{ Soil resistant-easy to clean } \\
\hline - soil resistance & 0 & \\
\hline -cleaning ability & 0 & \\
\hline \multicolumn{3}{|l|}{ Seat comfort } \\
\hline - Surface softness & a & \\
\hline - Humidity absorption & 0 & \\
\hline - Humidity transport & Q & \\
\hline - Static charge & & \\
\hline Recycling & & 口 \\
\hline
\end{tabular}


Abrasion resistance is usually tested by using Martindale, Taber, and Schopper devices. Each of these devices represents different methods, abrading motions, and abrading materials. The standards and specifications for abrasion resistance are given by BS 5690: $1991 \quad$ (Martindale), DIN $53 \quad 863 \quad 3 / 4$ (Martindale), DIN 538632 (Schopper), DIN 53754 (Taber), and UNE-EN ISO 12947-1/2/3 (Martindale). Moreover, different companies and laboratories have also designed their own devices and specific testing methods.

This paper analyzes and compares three abrasion resistance tests with different abrading materials for car seat upholstery fabrics. In addition, the relationship between the weight loss due to abrasion is expressed by a regression equation for the Martindale test, since this method is the most test used [6].

\section{TEST INSTRUMENTS}

Martindale, Schopper, and Transversal (developed by LEITAT [7]) abrasion test instruments were chosen to evaluate and compare the abrasion resistance of car seat upholstery. Similar national and international standards and specifications of a few car producers were used to identify the conditions for the pretesting and testing. Detailed information of the used instruments is described in a previous publication [8].

\section{TEST MATERIALS}

Car seat upholstery is usually tested in the form of a tri-laminate structure composed of the textile cover material, foam, and nonwoven support material on the back. The foam structure helps to lock the fibers together in the fabric and can give better results of the abrasion resistance. The nonwoven part gives dimensional stability to the sandwich structure.

For this study, the cover fabric was a soft velour surface of polyester (with a weight of $305.78 \mathrm{~g} / \mathrm{m}^{2}$, density of 13 stitches $/ \mathrm{cm}$, and yarn of $167 \mathrm{dtex}$ ) processed on a circular weft knitted machine (gauge E18) and raised on the machine that is responsible for the typical appearance of the ideal surface for car seat upholstery. This fabric, provided by a company that manufactures seat covers for several well-known European automotive manufacturers, is laminated with foam of different thickness and density and has a nonwoven on the back. The characteristics of the foams and nonwoven material used are shown in Table II.
All the specimens were conditioned in a controlled atmosphere of $23 \pm 2^{\circ} \mathrm{C}$ and relative humidity of $50 \pm 5 \%$ for not less than 24 hours prior to pretesting and testing.

TABLE II. Characteristics of the foam and nonwoven materials used in the studied upholstery.

\begin{tabular}{|l|l|c|}
\hline & \multicolumn{1}{|c|}{ Method } & Value \\
\hline Foam 3mm & & \\
\hline Density & ISO 1855 & $26.34 \pm 3 \mathrm{~kg} / \mathrm{m}^{3}$ \\
\hline Hardness & ISO 3386 & $6.4 \pm 2 \mathrm{kPa}$ \\
\hline Weight & ISO 9073-1 & $79 \pm 10 \mathrm{~g} / \mathrm{m}^{2}$ \\
\hline Foam 4,2 mm & & \\
\hline Density & ISO 1855 & $41.43 \pm 3 \mathrm{~kg} / \mathrm{m}^{3}$ \\
\hline Hardness & ISO 3386 & $6.6 \pm 2 \mathrm{kPa}$ \\
\hline Weight & ISO 9073-1 & $174 \pm 10 \mathrm{~g} / \mathrm{m}^{2}$ \\
\hline Foam 5mm & & \\
\hline Density & ISO 1855 & $49.80 \pm 3 \mathrm{~kg} / \mathrm{m}^{3}$ \\
\hline Hardness & ISO 3386 & $7.1 \mathrm{kPa} \pm 2 \mathrm{kPa}$ \\
\hline Weight & ISO 9073-1 & $249 \pm 10 \mathrm{~g} / \mathrm{m}^{2}$ \\
\hline Nonwoven & & \\
\hline Thickness & ISO 9073/2 & $0.81 \pm 0.15 \mathrm{~mm}$ \\
\hline Weight & ISO 9073-1 & $79 \pm 10 \mathrm{~g} / \mathrm{m}^{2}$ \\
\hline
\end{tabular}

With regard to abrasive materials, there are different abrasive papers with variations of used materials and grits, grit size and bond. Coated abrasives are made with abrasive grains adhered to the surface of flexible or semi-flexible backings such as paper, cloth, vulcanized fibers and plastic films. The most common shapes of these papers are sheets, usually 9 or 11 inches, and rolls. Different standards have been established for the grit size. The two most important standards are the United States CAMI and the European "P" grade. The FEPA system is the same as the ISO 6344 standard. Grit size refers to the size of the particles of the abrading materials embedded in the paper. The number corresponds to the number of meshes per linear inch in the grading sieve. The main characteristics of the abrasive papers used in this study are shown in Table III.

TABLE III. Characteristics of abrasive papers (according to FEPA-Standards 43-1:2006; 43-2:2006 and ISO 6344).

\begin{tabular}{ccc}
\hline $\begin{array}{c}\text { Grit } \\
\text { designation }\end{array}$ & Microgrits & $\begin{array}{c}\text { Average particle } \\
\text { diameter }(\boldsymbol{\mu m})\end{array}$ \\
\hline P320 & Very Fine & $46.2 \pm 1.5$ \\
P400 & Extra fine & $35.0 \pm 1.5$ \\
P600 & Extra fine & $25.8 \pm 1$ \\
\hline
\end{tabular}




\section{EXPERIMENTAL}

A pretesting procedure according to the standards and specifications for Martindale and Schopper was performed to identify the subjective conditions. Pressure (or force) per affected surface of the sample was identified as a subjective condition.

For Martindale, it is possible to apply pressure of $9 \mathrm{kPa}$ or $12 \mathrm{kPa}$ (UNE-EN ISO12947). The first one $(9 \mathrm{kPa})$ was taken as a suitable force to obtain as much as possible similar conditions, and pressure of $5 \mathrm{~N}$ for the Transversal instrument was taken as well. The number of cycles was defined according to the standard for Schopper. As was mentioned before, there is no standard for the Transversal method. However, the object is to identify similar conditions. During the pretesting, 5000 cycles were identified for the Transversal apparatus (a lower number of cycles had not given significant results of weight loss), and 1000 cycles were identified for Martindale (a higher number of cycles had given very high values of weight loss). These conditions are shown in Table IV.

TABLE IV. Conditions for testing.

\begin{tabular}{|c|c|c|c|c|}
\hline $\begin{array}{c}\mathrm{N}^{\circ} \text { of } \\
\text { samples }\end{array}$ & $\begin{array}{l}\mathrm{N}^{\circ} \text { of } \\
\text { cycles }\end{array}$ & $\begin{array}{c}\text { Size } \\
\text { simple, } \\
\text { diameter }\end{array}$ & $\begin{array}{c}\text { Abrasive } \\
\text { material }\end{array}$ & $\begin{array}{c}\text { Pressure/ } \\
\text { Force }\end{array}$ \\
\hline \multicolumn{5}{|c|}{ Martindale abrasion instrument } \\
\hline \multirow{3}{*}{$\begin{array}{l}\quad 4 \text { per } \\
\text { replication }\end{array}$} & \multirow{3}{*}{1.000} & \multirow{3}{*}{$38 \pm 5 \mathrm{~mm}$} & P320 & \multirow{3}{*}{$\begin{array}{c}9 \mathrm{kPa} \\
(0,430 \\
\mathrm{Kg}) \\
\end{array}$} \\
\hline & & & P400 & \\
\hline & & & P600 & \\
\hline \multicolumn{5}{|c|}{ Schopper abrasion instrument } \\
\hline \multirow{3}{*}{5} & \multirow{3}{*}{5.000} & \multirow{3}{*}{$100 \mathrm{~cm}^{2}$} & P320 & \multirow{3}{*}{$9,81 \mathrm{~N}$} \\
\hline & & & P400 & \\
\hline & & & P600 & \\
\hline \multicolumn{2}{|c|}{ Specimen curvature } & $\begin{array}{l}\text { Brushing } \\
\text { down the } \\
\text { specimen }\end{array}$ & \multicolumn{2}{|c|}{ Abrasion surface } \\
\hline \multicolumn{2}{|c|}{$5 \mathrm{~mm}$} & $\begin{array}{l}\text { After } \\
\text { every } 100 \\
\text { abrasion } \\
\text { rotations }\end{array}$ & \multicolumn{2}{|c|}{$50 \mathrm{~cm}^{2}$} \\
\hline \multicolumn{5}{|c|}{ Transversal } \\
\hline 5 (II) ${ }^{*}$ & \multirow{3}{*}{5.000} & \multirow{3}{*}{$21 \times 6 \mathrm{~cm}^{2}$} & P320 & \multirow{3}{*}{$5 \mathrm{~N}$} \\
\hline \multirow{2}{*}{$5(=)^{* *}$} & & & P400 & \\
\hline & & & P600 & \\
\hline \multicolumn{5}{|c|}{ VALUATION: Weight loss in \% } \\
\hline
\end{tabular}

\section{RESULTS AND DISCUSSION}

With the goal of comparing abrasive resistance instruments a Latin square design was planned, according to Table $\mathrm{V}$, where $\mathrm{M}$ is Martindale; $\mathrm{S}$, Schopper; and H, Transversal). Table VI shows the results of testing.
The factor of interest is the type of instrument and two block factors were controlled: type of abrasive paper and height of the foam in the tri-laminate structure. Therefore, the courses and the wales represent two restrictions on the random variable. The Latin square design $3 \times 3$ has two degrees of freedom; therefore it is necessary to make replications by increasing the residual degrees of freedom.

TABLE V. Design for analysis of abrasive test methods.

\begin{tabular}{|c|c|c|c|c|}
\hline & \multicolumn{4}{|c|}{ Abrasive Test Methods } \\
\hline & \multirow{2}{*}{$\begin{array}{l}\text { Foam } \\
(\mathrm{mm})\end{array}$} & \multicolumn{3}{|c|}{ Abrasive paper } \\
\hline & & P320 & $\mathrm{P} 400$ & P600 \\
\hline \multirow{3}{*}{ Replication I } & 3 & $\mathbf{S}$ & $\mathbf{M}$ & $\mathbf{H}$ \\
\hline & 4.2 & $\mathbf{H}$ & $\mathrm{S}$ & $\mathbf{M}$ \\
\hline & 5 & $\mathbf{M}$ & $\mathbf{H}$ & $\mathbf{S}$ \\
\hline & & & & \\
\hline \multirow{3}{*}{ Replication II } & 3 & $\mathbf{S}$ & $\mathbf{H}$ & $\mathbf{M}$ \\
\hline & 4.2 & $\mathbf{M}$ & $\mathbf{S}$ & $\mathbf{H}$ \\
\hline & 5 & $\mathbf{H}$ & $\mathbf{M}$ & $\mathrm{S}$ \\
\hline
\end{tabular}

TABLE VI. Results of the abrasive test methods.

\begin{tabular}{|c|c|c|c|c|}
\hline \multirow{4}{*}{ Replication I } & \multicolumn{4}{|c|}{ Weight loss (\%) } \\
\cline { 2 - 5 } & \multirow{2}{*}{$\begin{array}{c}\text { Foam } \\
(\mathrm{mm})\end{array}$} & \multicolumn{3}{|c|}{ Abrasive paper } \\
\cline { 2 - 5 } & 3 & 1.31 & 6.02 & 1.44 \\
\cline { 2 - 5 } & 4.2 & 2.53 & 0.51 & 2.96 \\
\hline & 5 & 4.93 & 1.38 & 0.35 \\
\hline \multirow{3}{*}{ Replication II } & 3 & & & \\
\cline { 2 - 5 } & 4.2 & 8.70 & 0.51 & 1.57 \\
\cline { 2 - 5 } & 5 & 2.87 & 3.65 & 0.35 \\
\hline
\end{tabular}

The results can be explained by the three-way analysis of variance model in Eq. (1):

$$
\mathrm{y}_{\mathrm{ijkl}}=\mu+\alpha_{\mathrm{i}}+\beta_{\mathrm{j}}+\tau_{\mathrm{k}}+\gamma_{\mathrm{l}}+\varepsilon_{\mathrm{ijkl}}
$$

where $\mu$ is the overall mean weight loss, $\alpha_{i}$ is the effect of course direction (structure), $\beta_{\mathrm{j}}$ is the effect of wale direction (paper), $\tau_{\mathrm{k}}$ is the treatment effect (instrument) and $\gamma_{1}$ is the replication effect.

And the appropriate hypothesis to contrast is Eq. (2):

$$
\mathrm{H}_{0}=\tau_{\mathrm{k}}=0, \mathrm{k}=\mathrm{M}, \mathrm{S}, \mathrm{H} \text { apparatus }
$$

The analysis of variance is presented in Table VII. The statistical $\mathrm{F}$ instrument is significant to $1 \%$ (its value $\mathrm{P}$ gives a significance level equal to 0.000 , indicating that the effect of the abrasive test method is great). The $88.7 \%$ of variability of results $\left(\mathrm{R}^{2}\right)$ is explained by the model represented in Eq. (1). 
TABLE VII. Analysis of Latin-square design variance.

\begin{tabular}{|l|c|c|c|c|c|}
\hline $\begin{array}{c}\text { Source of } \\
\text { variation }\end{array}$ & $\begin{array}{c}\text { Degrees } \\
\text { of } \\
\text { freedom }\end{array}$ & $\begin{array}{c}\text { Sum of } \\
\text { squares }\end{array}$ & $\begin{array}{c}\text { Mean } \\
\text { square }\end{array}$ & $\begin{array}{c}\text { F- } \\
\text { Ratio }\end{array}$ & $\begin{array}{c}\text { P } \\
\text { Value }\end{array}$ \\
\hline Instrument & 2 & 59.93 & 29.96 & 24.16 & 0.000 \\
\hline Papers & 2 & 10.58 & 5.29 & 4.26 & 0.046 \\
\hline Structure & 2 & 0.93 & 0.46 & 0.37 & 0.696 \\
\hline Replication & 1 & 0.61 & 0.61 & 0.49 & 0.500 \\
\hline Residual & 10 & 12.48 & 1.24 & & \\
\hline TOTAL & 17 & 84.53 & & & \\
\hline
\end{tabular}

There are differences between the averages of the instrument factor results. The graphic of averages considering the confidence intervals of $95 \%$, according to the LSD (minimum significant difference), is presented in Figure 1 and detects the differences $\mathrm{H} \neq \mathrm{M}, \mathrm{M} \neq \mathrm{S}$. Moreover, there are no significant differences between these two devices, $\mathrm{H}=\mathrm{M}$. This statistical test gives the practical conclusion that the Martindale abrasive test method generates more loss than the Transversal and Schopper instruments.

Since the courses and the wales of the square design represent restrictions on the random, the $F$ tests in ANOVA are not exact; however, as an approximate procedure to investigate the effect of the block factors they are accepted in practice. It is interesting to compare the abrasive power of the papers $\left(\mathrm{H}_{0}=\beta_{\mathrm{J}}\right.$ $=0, j=320,400,600)$ : there are differences between the averages of the abrasive paper factor results. The graphic of averages considering the confidence intervals of $95 \%$ according to the LSD (minimum significant difference) is presented in Figure 2 and detects the differences $\mathrm{P} 320 \neq \mathrm{P} 400, \mathrm{P} 320 \neq \mathrm{P} 600$. This statistical test gives the conclusion that $\mathrm{P} 320$ paper is more abrasive than $\mathrm{P} 400$ and $\mathrm{P} 600$, and there are no significant differences between P400 and P600.

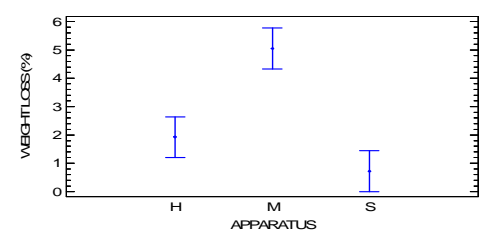

FIGURE 1. Means instrument and 95.0 percent LSD intervals.

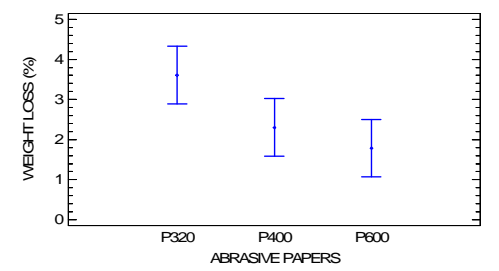

FIGURE 2. Means paper and 95,0 percent LSD intervals.

Journal of Engineered Fibers and Fabrics

Volume 8, Issue 3 - 2013
The purpose of this second part is to develop a model of the abrasion kinetic by studying the relation between the weight loss and the number of cycles using the most well-known instrument for automotive manufacturers: the Martindale one. The first step was to identify the maximum number of cycles until the appearance of the break of the structure. The given results for each structure were used as a maximum number of the abrasion kinetic and divided into four parts $(25 \%, 50 \%, 75 \%$ and $100 \%)$. The weight loss due to abrasion is represented in Figures 3, 4 and 5 and the relationship between the weight loss and the abrasion cycles can be modelled by the single regression equations shown in Table VIII.
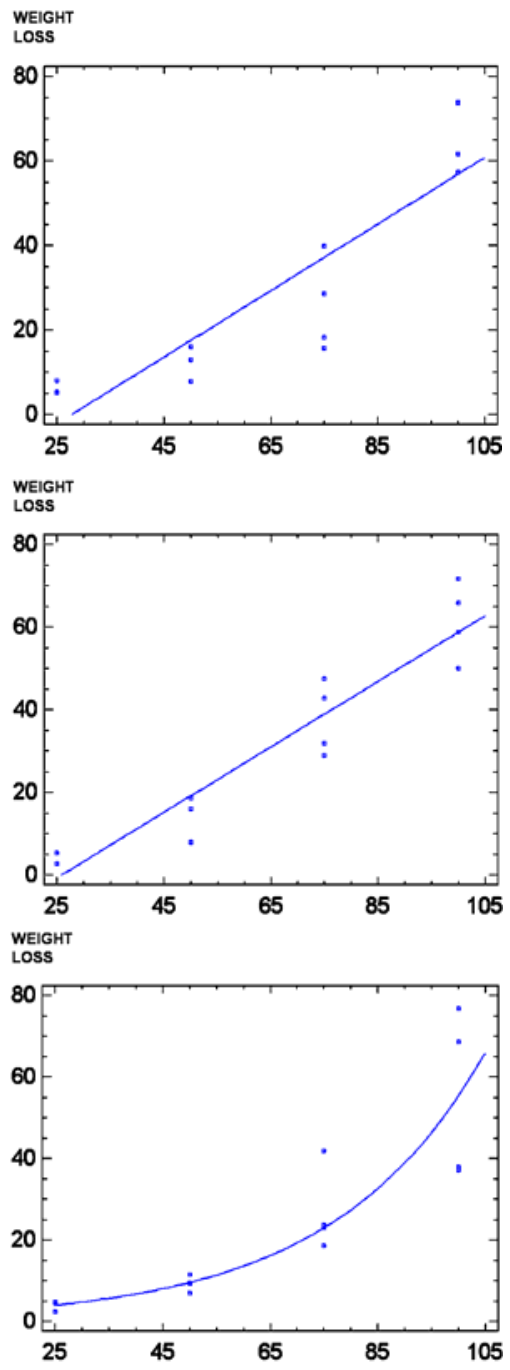

FIGURE 3. Abrasion kinetic with Martindale using the abrasive paper P320. Structure 3 (top); Structure 4, 2 (middle) and Structure 5 (bottom). 
The manner of weight loss of Structure 3 and 4.2 is similar. When paper is more aggressive (P320), the behavior of weight loss is linear. Using the paper $\mathrm{P} 400$ and $\mathrm{P} 600$, at the beginning the weight loss is smaller, and after a certain number of cycles bigger. In the case of Structure 5, the manner of weight loss is different; at the beginning, the weight loss is smaller, and after a certain number of cycles bigger (P320). When the number of the paper is bigger, the weight loss has a tendency to reach a linear curve.

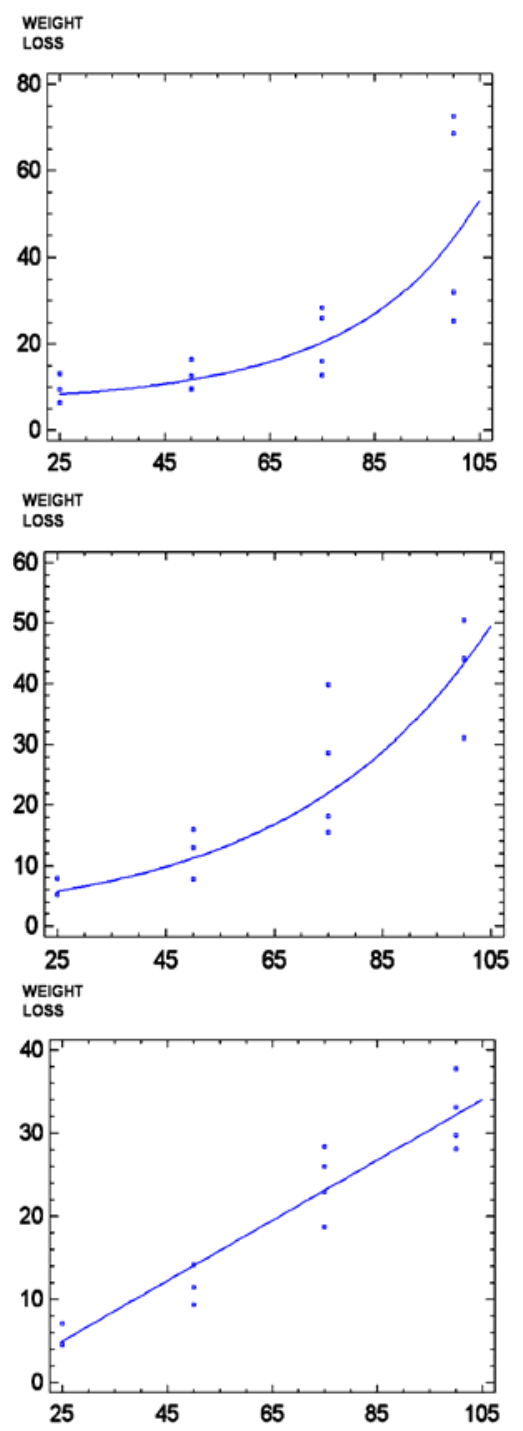

FIGURE 4. Martindale abrasion kinetic using the abrasive paper P400.Structure 3 (top); Structure 4, 2 (middle) and Structure 5 (bottom).

Plots of weight loss vs abrasion cycles (Figures 3, 4 and 5) show concave and linear abrasion kinetics. In accordance with these eight types of abrasion kinetics, several regression models have been established (see Table VIII). Models established to explain the phenomenon of the abrasion are simple regressions, quadratic, and logarithmic-squared regressions. Regression analyses are shown in Table IX.

Since the P-value in the ANOVA table (Table IX) is less than 0.05 there is a statistically significant relationship between weight loss (variable y) and number of cycles (variable $\mathrm{x}$ ) at the $95 \%$ confidence level. The R-squared statistic (adjusted for d. f.) indicates the model explaining the variability between $63 \%$ and $91 \%$ of the response. If the coefficient of determination is $63 \%$, this means that the residual sum of squares, which includes the experimental error, is $37 \%$ (and the same for $91 \%$ ).

On the other hand, regarding the pure error due to the repetitions of the cycle, in Figures 3, 4 and 5 a high variability can be seen due to the differences that take place in the four plates of the used Martindale [8].
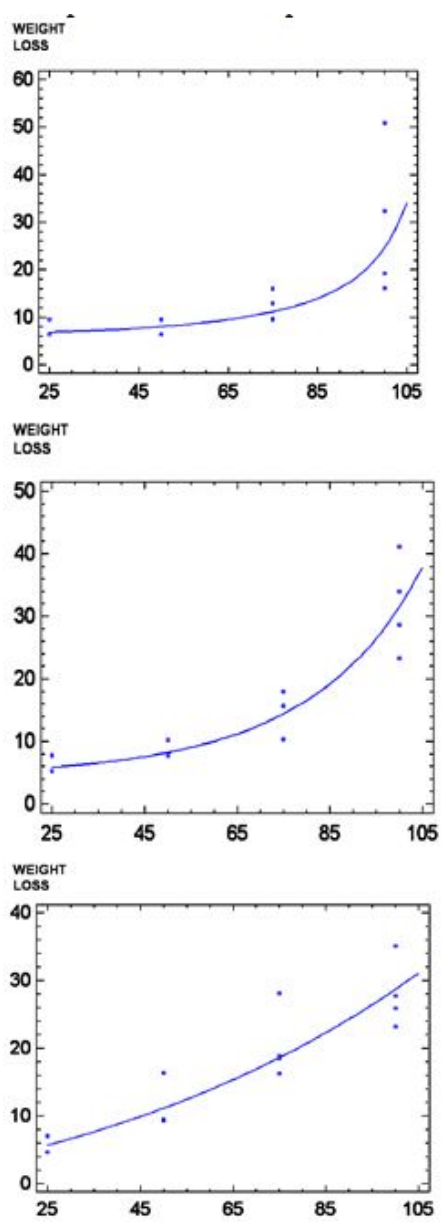

FIGURE 5. Martindale abrasion kinetic using the abrasive paper P600. Structure 3 (top); Structure 4,2 (middle) and Structure 5 (bottom). 
TABLE VIII. Equations of regressions for Martindale apparatus.

\begin{tabular}{|c|c|c|c|}
\hline Paper & \multicolumn{2}{|c|}{$\begin{array}{c}\text { Structure/ } \\
\text { Cycles }\end{array}$} & $\begin{array}{c}\text { Regression } \\
\text { Model and equation of } \\
\text { the fitted model }\end{array}$ \\
\hline \multirow[b]{3}{*}{ P320 } & 3 & 2200 & $\begin{array}{c}\text { Lineal } y=a+b x \\
y=-21.86+0.7862 x\end{array}$ \\
\hline & 4.2 & 1800 & $\begin{array}{c}\text { Lineal } y=a+b x \\
y=-20.52+0.7917 x\end{array}$ \\
\hline & 5 & 3200 & $\begin{array}{c}\text { Quadratic } \mathrm{y}=\mathrm{a}+\mathrm{bx}+\mathrm{cx}^{2} \\
\mathrm{y}=10.075-0.4745 \mathrm{x}+0.00925 \mathrm{x}^{2}\end{array}$ \\
\hline \multirow[b]{3}{*}{ P400 } & 3 & 7500 & $\begin{array}{c}\text { Logarithmic-squared } y=\exp \left(a+b x^{2}\right) \\
y=\exp \left(1.950+0.0001710 \mathrm{x}^{2}\right)\end{array}$ \\
\hline & 4.2 & 5000 & $\begin{array}{c}\text { Quadratic } \mathrm{y}=\mathrm{a}+\mathrm{bx}+\mathrm{cx}^{2} \\
\mathrm{y}=4.829-0.08799 \mathrm{x}+0.004674 \mathrm{x}^{2}\end{array}$ \\
\hline & 5 & 12000 & $\begin{array}{c}\text { Lineal } \mathrm{y}=\mathrm{a}+\mathrm{bx} \\
\mathrm{y}=-4.081+0.3624 \mathrm{x}\end{array}$ \\
\hline \multirow[b]{3}{*}{ P600 } & 3 & 12000 & $\begin{array}{c}\text { Logarithmic-squared } \\
\mathrm{y}=\exp \left(\mathrm{a}+\mathrm{bx}^{2}\right) \\
\mathrm{y}=\exp \left(1.764+0.0001446 \mathrm{x}^{2}\right)\end{array}$ \\
\hline & 4.2 & 8400 & $\begin{array}{c}\text { Quadratic } y=a+b x+c x^{2} \\
y=11.98-0.3754 x+0.005701 x^{2}\end{array}$ \\
\hline & 5 & 20800 & $\begin{array}{c}\text { Quadratic } y=a+b x+c x^{2} \\
y=0.3019+0.1862 x+0.000933 x^{2}\end{array}$ \\
\hline
\end{tabular}

TABLE IX. Regression analyses abrasion kinetic using Martindale.

\begin{tabular}{|l|l|l|c|c|c|c|c|}
\hline \multicolumn{9}{|c|}{ P320 } \\
\hline Struct. & Source & Sum of Squares & Df & Mean Square & F-Ratio & P-Value & R-squared \\
\hline & Model & 7727.17 & 1 & 7727.17 & 54.48 & 0.0000 & 78.10 \\
\hline $\mathbf{3}$ & Residual & 1985.74 & 14 & 141.84 & & & \\
\hline & Total & 9712.91 & 15 & & & & \\
\hline & Model & 7834.47 & 1 & 7834.47 & 123.51 & 0.0000 & 89.09 \\
\hline $\mathbf{4 . 2}$ & Residual & 888.06 & 14 & 63.43 & & & \\
\hline & Total & 8722.53 & 15 & & & & \\
\hline & Model & 6349.84 & 2 & 3174.92 & 25.63 & 0.0000 & 76.66 \\
\hline $\mathbf{5}$ & Residual & 1610.26 & 13 & 123.87 & & & \\
\hline & Total & 7960.10 & 15 & & & & \\
\hline \\
\hline
\end{tabular}

The abrasion resistance can be measured according to two physical aspects: weight loss due to abrasion action and number of abrasion cycles needed to produce textile breakage. With regard to this second aspect the abrasive power is inverse to breaking cycles: with high power the number of breaking 
cycles is smaller. In accordance with this fact, to compare the abrasive power among the papers, the values of breaking are divided as presented in Table $X$; the last two columns show the relationships between each paper and their immediate predecessor according to the established sequence. Table XI shows the average results: paper 400 is three times less abrasive than P320; P600 is two times less abrasive than P400; and P600 is six times less abrasive than P320.

TABLE X. Relation between abrasive paper.

\begin{tabular}{|c|c|c|c|c|}
\hline Structure & $\begin{array}{c}\text { Abrasive } \\
\text { paper }\end{array}$ & $\begin{array}{c}\text { Breaking } \\
\text { Cycle }\end{array}$ & \multicolumn{2}{|c|}{ Level of abrasion } \\
\hline \multirow{3}{*}{3} & $\mathrm{P} 320$ & 2200 & 1 & 1 \\
\cline { 2 - 5 } & $\mathrm{P} 400$ & 7500 & 3.409 & 1 \\
\cline { 2 - 5 } & $\mathrm{P} 600$ & 12000 & 5.454 & 1.600 \\
\hline \multirow{3}{*}{4.2} & $\mathrm{P} 320$ & 1800 & 1 & 1 \\
\cline { 2 - 5 } & $\mathrm{P} 400$ & 5000 & 2.777 & 1 \\
\cline { 2 - 5 } & $\mathrm{P} 600$ & 8400 & 4.666 & 1.680 \\
\hline \multirow{3}{*}{5} & $\mathrm{P} 320$ & 3200 & 1 & 1 \\
\cline { 2 - 5 } & $\mathrm{P} 400$ & 12000 & 3.750 & 1 \\
\cline { 2 - 5 } & $\mathrm{P} 600$ & 20800 & 6.500 & 1.733 \\
\hline
\end{tabular}

TABLE XI. Paper ratio counted from the breaking cycle.

\begin{tabular}{|c|c|c|}
\hline RELATION PAPER & Average Value & Ratio Value \\
\hline P400/P320 & 3.312 & $3: 1$ \\
\hline P600/P400 & 1.671 & $2: 1$ \\
\hline P600/P320 & 5.540 & $6: 1$ \\
\hline
\end{tabular}

\section{CONCLUSIONS}

In this paper, three abrasion test methods have been used for the investigation of automobile seat covers: Martindale, Schopper and Transversal (LEITAT). According to the standards and specifications for Martindale and Schopper, pretesting procedure conditions have been identified, and conditions for the Transversal device have been obtained as well. Afterward, these instruments have been compared.

The main results in this study can be summarized as follows:

$>\quad$ The results obtained using Latin square design show significant differences between Martindale and other methods. There are no significant differences between Schopper and Transversal.

By measuring weight loss at $25 \%, 50 \%$, $75 \%$ and $100 \%$ of the number of abrasion cycles needed to obtain upholstery material breaking, the relationship between the weight loss and the abrasion cycles can be modelled by simple regression equations, quadratic regression and logarithmicresponse $v s$ square-predictor. These equations depend on abrasion paper and high textile structure: when the

Journal of Engineered Fibers and Fabrics

Volume 8, Issue 3 - 2013 paper is more aggressive (P320), the behavior of weight loss is linear. Using the paper P400 and P600, at the beginning the weight loss is smaller, and after a certain number of cycles bigger.

$>\quad$ The following paper ratios counted from the breaking cycle have been found: P400/P320 (3/1), P600/P400 (2/1), P600/P320 (6/1).

Results of this study can be used by academic researchers and companies to identify adequate conditions for test apparatus.

\section{REFERENCES}

[1] Karthik, T.; Murugan, R.; Automotive industryhigh potential market for nonwovens. Technical Textiles. Innovation, Technology, Application, 2010, 3, 99-101.

[2] Fung, W.; Hardcastle, M.; Textiles in automotive engineering. The Textile Institute, Woodhead Publishing Limited: Cambridge, 2001.

[3] Shishoo, R. (editor); Textile advances in the automotive industry. The Textile Institute, Woodhead Publishing Limited: Cambridge, 2008.

[4] Pamuk, G.; Çeken, F.; Research on the Breaking and Tearing Strengths and Elongation of Automobile Seat Cover Fabrics Textile Research Journal, 2009, 79(1), 47-58.

[5] Grebe, R.T.; Automotive textiles requirements and performance profiles. Melliand International, 2000, 6, 226-228.

[6] Castellar, M.D.; Saurí R.M.; Martí M.; Manich A.M. Further Progress on the Abrasion kinetic modelling of woven fabrics using the Martindale abrasion tester. Journal of the Textile Institute, 2004, 95, 369-379.

[7] LEITAT Technological Center. http://www.leitat.org/

[8] Jerkovic, I.; Pallares, J.M.; Capdevila, X. Study of the abrasion resistance in the Upholstery of automobile seats. Autex Research Journal, 2010, 10(1), 14-20.

\section{AUTHORS' ADDRESSES \\ Ivona Jerkovic \\ Josep Maria Pallarés \\ Monica Ardanuy, PhD \\ Xavier Capdevila PhD}

Universitat Politècnica de Catalunya

Textile and Paper Engineering Department

ETSEIAT

Edifici TR4, Despatx 222

C/ Colom 11

Terrassa, Barcelona 08222

SPAIN 